\title{
Level of awareness among aganwadi workers regarding nutrition and health care
}

See end of the paper for authors' affiliations

\section{MUKTA GARG}

Department of Human

Development, M.A.B. College of

Home Science, C.S.A. University of

Agriculture and Technology,

KANPUR (U.P.) INDIA
ABSTRACT : The word Aganwadi means "courtyard shelter" in Hindi. These centers were started by the Indian government in 1975 as part of the Integrated Child Development Services programme to combat child hunger and malnutrition. Aganwadi are India's primary tool against the scourges of child malnourishment, infant mortality and curbing preventable diseases such as polio. As the Aganwadi worker is the key person in the programme, her level of awareness regarding this project will definitely help in better outcomes, and development of the villages. Therefore, present study was under taken to find out the level of awareness of Aganwadi workers and it's relation to their back ground characteristics. For this purpose a total number of 120 AWWs was selected randomly from two blocks of district Faizabad they were interviewed with the help of self prepared interview schedule. Out of total AWWs maximum 64.2 per cent belonged to 36-50 years age group. Awareness regarding nutrition and health care maximum (97.5\%) of AWWs were having complete knowledge about food item for a new born babies and followed by right age to introduce semi solid food (94.2\%) result indicates that in all categories AWWS of 36-50 years age group had better knowledge, the awareness of AWWs was different, they were not equally aware. The positive correlation ship was found between the level of awareness and the educational status of AWWs. Thus it can be said that education helps in boots up the level of awareness.

KEY WORDS: Awareness, Nutrition, Health care, Aganwadi workers

- HOW TO CITE THIS PAPER : Garg, Mukta and Malika, Shashi (2016). Level of awareness among aganwadi workers regarding nutrition and health care. Asian J. Home Sci., 11 (1) : 281-284, DOI: 10.15740/ HAS/AJHS/11.1/281-284. 